\title{
Non-Destructive Imaging of Water Permeation through Cementitious Materials Using MRI
}

\author{
Yuya Sakai, Yuki Yokoyama, Toshiharu Kishi \\ Institute of Industrial Science, The University of Tokyo, Tokyo, Japan \\ Email: ysakai@iis.u-tokyo.ac.jp
}

How to cite this paper: Sakai, Y., Yokoyama, Y. and Kishi, T. (2017) Non-Destructive Imaging of Water Permeation through Cementitious Materials Using MRI. Open Journal of Civil Engineering, 7, 378-388. https://doi.org/10.4236/ojce.2017.73026

Received: July 13, 2017

Accepted: August 12, 2017

Published: August 15, 2017

Copyright (C) 2017 by author and Scientific Research Publishing Inc. This work is licensed under the Creative Commons Attribution International License (CC BY 4.0).

http://creativecommons.org/licenses/by/4.0/

(c) (i) Open Access

\begin{abstract}
In this study, water permeation through cementitious materials was observed using magnetic resonance imaging (MRI). The influence of cement type on the magnetic resonance signal was studied subsequent to determining the parameters required for imaging. Consequently, adequate imaging of water permeating through hardened cement paste (HCP) made with white Portland cement was achieved, while water permeation through ordinary Portland cement-based HCP yielded poor signal. HCPs maintained at various levels of relative humidity $(\mathrm{RH})$ were observed, and the signal was detected only from those maintained at an $\mathrm{RH}$ of higher than $85 \%$. The water permeation depths in HCP were observed by using MRI, and the measured depths were compared to those measured via a spraying water detector on the split surface of the specimens. As a result, good agreement was confirmed between the two methods. Additionally, MRI was applied to concrete specimens; although it was found that water was not detected when a lightweight aggregate was used, water permeation through concrete with limestone aggregate was detectable via MRI. MRI will help in understanding how water permeation causes and accelerates concrete deteriorations such as rebar corrosion and freezing and thawing.
\end{abstract}

\section{Keywords}

MRI, Cement Paste, Concrete, Water Permeation, Non-Destructive Testing

\section{Introduction}

Water is known to yield deleterious effects on concrete structures. To observe the depth of water permeation through concrete, the concrete specimen can be split to measure the depth of the surface colour changes [1] [2]. However, the determination of water permeation depth in concrete is difficult because $70 \%$ to 
$80 \%$ of the split surface area is aggregate, and the colour change due to permeated water is generally only visible in the cement paste. Some researchers have cut concrete specimens and dried them to evaluate mass changes due to water transfer, and to determine the moisture distribution [3]. Alternatively, humidity sensors can be used to measure the moisture distribution [4] or water penetration depth in concrete [5]. Justnes et al. [6] and Pleinert et al. [7] applied neutron radiography to observe water in cementitious materials; however, it was found that the sample thickness had to be limited to a few centimetres to allow the neutron ray to completely pass through the sample. The above methods only yield one- to two-dimensional information.

In this paper, magnetic resonance imaging (MRI) was used to observe water permeation through concrete. MRI can acquire three-dimensional information because it receives radio-frequency signals from any position in the sample at which hydrogen atoms are present. Moreover, it is non-destructive and enables the observation of water movement in real time. However, a disadvantage of this method is that, as strong magnets are implemented, MRI cannot be applied to reinforced concrete because of the strong attraction of steel; additionally, magnetic materials such as steel bars cause distortion of the obtained images. In their study using MRI to observe concrete structures, Marfisi et al. [8] reported that magnetic components in ordinary Portland cement (OPC) affect the captured images. In addition, Marfisi et al. [9] employed MRI to evaluate fractures in concrete. They reported that limestone and quartz aggregates are preferred to observe concrete via MRI and that granite is not suitable. Kaufmann et al. [10] implemented MRI to observe water permeation through concrete specimens, but as they used OPC, the obtained images were not clear. It was found that deuterated water can yield marginal improvements in the image, but it is expensive. Additionally, Kaufmann et al. did not explicitly confirm whether the penetration depth captured via MRI was correct, as they merely calculated the depth via determination of mass increase due to immersion, which was accomplished by comparing the dry and saturated masses.

The objective of this paper is to study the applicability of MRI to the observation of water permeation through concrete. To begin, the necessary parameters for MRI were determined by evaluating the hardened cement paste (HCP) made with white Portland cement (WPC). WPC was used because magnetic components in OPC affected the captured image, as will be discussed in a later section. Then, HCPs made with WPC and maintained at various levels of relative humidity (RH) were observed via MRI to determine the threshold of water detection. Next, HPCs dried at various temperatures were soaked in water; the permeation depth was subsequently imaged via MRI, and the observed depth was compared to the depth as measured on the splitting surface. Lastly, concrete specimens with lightweight aggregate (LWA) and limestone aggregate (LSA) were prepared and observed via MRI to determine the effects of aggregates on the obtained images. Concrete with the commonly used granite aggregate was not stu- 
died because Marfisi et al. [8] has already reported that the obtained MRI image of concrete containing granite was distorted.

\section{MRI Background Information (Hashemi et al. [11])}

The general principle of MRI is that it constructs images from the signal emitted from the hydrogen nuclei in the object under observation. To image, a strong magnetic field is first applied to the object. When an object containing hydrogen atoms enters the external magnetic field, the spin of the nuclei is oriented to the direction of the magnetic field; this direction is generally assumed as the $Z$ axis. When a radio-frequency pulse with the same frequency as the proton spin is applied to the object, the axis of the spin inclines towards the $X$ - $Y$ plane, which is orthogonal to the $Z$ axis. This inclination angle is called the flip angle. The inclined spin is recovered towards the $Z$ axis after the radio-frequency pulse has ceased. Thus, MRI constructs images according to the signal that is emitted from the hydrogen nuclei as the spin recovers from the $X$ - $Y$ plane to the $Z$ axis. The parameters describing the recovery of the $Z$-axis component $\left(M_{z}\right)$ and decay of the $X$ - $Y$-plane component $\left(M_{X Y}\right)$ are $T_{1}$ and $T_{2}$, respectively. $T_{1}$ and $T_{2}$ show the relaxation curves expressed by Equation (1) and Equation (2), respectively.

$$
\begin{aligned}
& M_{Z}(t)=M_{0}\left(1-\mathrm{e}^{-t / T_{1}}\right) \\
& M_{X Y}(t)=M_{0}\left(1-\mathrm{e}^{-t / T_{2}}\right)
\end{aligned}
$$

$T_{1}$ and $T_{2}$ vary according to the mobility of hydrogen nuclei. The parameters for MRI observation must be optimized to obtain a clear image. The echo time ( $T_{E}$ : time interval between radio-frequency pulse and signal acquisition) and repetition time ( $T_{R}$ : time interval of radio-frequency pulse) are the most important parameters.

Marfisi et al. [8] used $T_{E}=3.5 \mathrm{~ms}$ and $T_{R}=100 \mathrm{~ms}$ to obtain MRI images of water in concrete. However, these $T_{E}$ and $T_{R}$ values cannot be used because these parameters vary according to the magnetic density. Marfisi et al. employed MRI with a magnetic density of $2 \mathrm{~T}$, while the MRI used in this study applies $3 \mathrm{~T}$. $T_{2}$ is obtained only when a perfectly uniform external magnetic field is applied; however, as real external magnetic fields are always non-uniform, the actual acquired signal is denoted as $T_{2}^{*}$, in distinction from $T_{2}$.

\section{Experimental Methods}

\subsection{Specimens}

The material properties are shown in Table 1 . HPCs of $\varphi 50 \times 100 \mathrm{~mm}$ and water-to-cement ratio (W/C) of 0.4 were respectively prepared using OPC and WPC. The specimens used to study the effects of RH via imaging were sealcured up to 28 days following casting, and then maintained at a temperature of $20^{\circ} \mathrm{C}$ under $60 \% \mathrm{RH}$ for 1 month. These specimens were cut into 2 -cm-thick slices via a water-cooling cutter and dried under conditions of $20^{\circ} \mathrm{C}$ and $60 \% \mathrm{RH}$ 
Table 1. Material specifications.

\begin{tabular}{|c|c|}
\hline Cement & $\begin{array}{l}\text { Ordinary Portland cement (density: } 3.15 \mathrm{~g} / \mathrm{cm}^{3} \text {, specific surface area: } 4110 \mathrm{~cm}^{2} / \mathrm{g} \text { ) } \\
\text { White Portland cement (density: } 3.05 \mathrm{~g} / \mathrm{cm}^{3} \text {, specific surface area: } 3440 \mathrm{~cm}^{2} / \mathrm{g} \text { ) }\end{array}$ \\
\hline Sand & $\begin{array}{l}\text { Artificial lightweight sand } \\
\text { (oven-dry density: } 1.65 \mathrm{~g} / \mathrm{cm}^{3} \text {, water absorption: } 15 \%, \mathrm{FM}: 2.75 \text { ) } \\
\text { Limestone sand } \\
\text { (surface dry density: } 2.65 \mathrm{~g} / \mathrm{cm}^{3} \text {, water absorption: } 2.42 \%, \mathrm{FM}: 3.60 \text { ) }\end{array}$ \\
\hline Gravel & $\begin{array}{l}\text { Artificial lightweight gravel (oven-dry density: } 1.29 \mathrm{~g} / \mathrm{cm}^{3} \text {, } \\
\text { maximum size: } 20 \mathrm{~mm} \text {, water absorption: } 28 \%, \mathrm{FM}: 6.35 \text { ) } \\
\text { Limestone gravel (surface dry density: } 2.70 \mathrm{~g} / \mathrm{cm}^{3}, \\
\text { maximum size: } 20 \mathrm{~mm} \text {, water absorption: } 0.41 \%, \mathrm{FM}: 7.68 \text { ) }\end{array}$ \\
\hline
\end{tabular}

for 2 weeks. Then, these cut samples were stored in desiccators at 76\%, 85\%, 98\% or $100 \%$ RH for 1 month and subsequently imaged via MRI. After MRI, the samples were oven-dried at $105^{\circ} \mathrm{C}$ for three days, and mass decrease of the sample due to drying was divided by the mass of the sample after it was oven-dried to evaluate moisture content. In a similar manner, HPCs used to evaluate the effects of cement type were seal-cured for 28 days subsequent to casting. These specimens were dried under conditions of $20^{\circ} \mathrm{C}$ and $60 \% \mathrm{RH}$ for 1 month, $40^{\circ} \mathrm{C}$ and $10 \% \mathrm{RH}$ for 2 weeks or $105^{\circ} \mathrm{C}$ for $3 \mathrm{~d}$. After drying, they were each soaked in 1 -cm-deep water for $3 \mathrm{~d}$ in a covered container prior to imaging as shown in Figure 1. Then, the specimens were split and a water leakage testing agent, MORAYMILLE (TASETO, Kanagawa, Japan), was applied to measure the water permeation depth.

The material properties and mix design of the concrete specimens are provided in Table 1 and Table 2, respectively. WCP was used to prepare concrete specimens of $\varphi 100 \times 200 \mathrm{~mm}$. Concrete specimens with LWA were demoulded $24 \mathrm{~h}$ after casting and dried at $105^{\circ} \mathrm{C}$ for $6 \mathrm{~d}$. The specimens were then soaked in 1 -cm-deep water for $3 \mathrm{~d}$ and imaged via MRI. Three concrete specimens with LSA were cast; of these, two of them were demoulded $24 \mathrm{~h}$ after casting and dried at $105^{\circ} \mathrm{C}$ or $20^{\circ} \mathrm{C}(60 \% \mathrm{RH})$ until MRI imaging was performed at an age of $48 \mathrm{~h}$. The remaining specimen was demoulded immediately prior to MRI imaging following $48 \mathrm{~h}$ aging. After imaging, the specimens maintained at $105^{\circ} \mathrm{C}$ were once again stored at $105^{\circ} \mathrm{C}$, while the remaining specimens were stored in a $20^{\circ} \mathrm{C}$ chamber under $60 \% \mathrm{RH}$. Once aged for $18 \mathrm{~d}$, they were each soaked in 1 -cm-deep water in an open-air container for $2 \mathrm{~d}$ prior to secondary imaging.

\subsection{Pore Structure Analysis}

The pore structure of the HCPs dried under conditions of $40^{\circ} \mathrm{C}$ and $10 \% \mathrm{RH}$ for 2 weeks was analysed via mercury intrusion porosimetry (MIP). The samples for MIP were collected from the HCP at depths greater than $2 \mathrm{~cm}$ from the surface. The collected samples were subsequently immersed in acetone for $24 \mathrm{~h}$ and dried for $24 \mathrm{~h}$ via the D-Dry method, in which the sample is equilibrated with ice at $-79^{\circ} \mathrm{C}$, prior to performing MIP. 


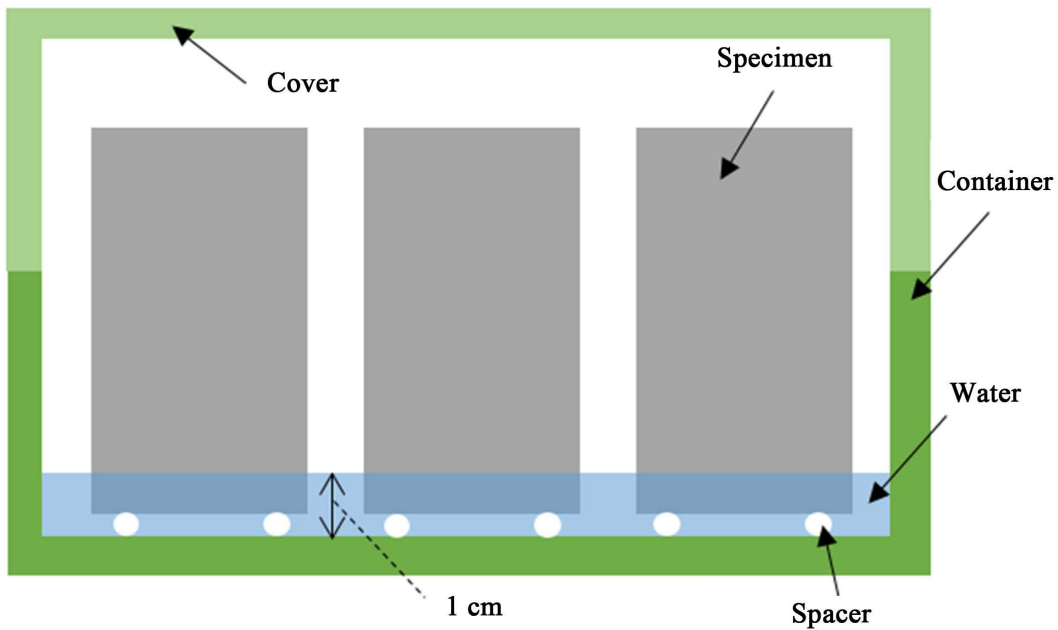

Figure 1. Schematic of water absorption (in covered container).

Table 2. Mix design.

\begin{tabular}{ccccccc}
\hline \multirow{2}{*}{ Name } & \multirow{2}{*}{ Aggregate type } & W/C $(\%)$ & \multicolumn{4}{c}{ Mass per unit volume $\left(\mathrm{kg} / \mathrm{m}^{3}\right)$} \\
\cline { 4 - 7 } & & & W & C & S & G \\
\hline Concrete with LWA & Lightweight & 55 & 174 & 316 & 535 & 601 \\
Concrete with LSA & Limestone & 60 & 170 & 283 & 774 & 1087 \\
\hline
\end{tabular}

\subsection{Determination of $T_{1}$ and $T_{2}^{*}$}

The MAGNETOM Prisma MRI (SIEMENS, Munich, Germany), equipped with a magnetic flux density of $3 \mathrm{~T}$, was used for MRI imaging. To determine the optimum parameters for imaging the prepared samples, the relaxation times of $T_{1}$ and $T_{2}^{*}$ were studied. $T_{1}$ was calculated via the following equation.

$$
T_{1}=-T_{R} / \ln \left(\frac{\frac{S_{2}}{\sin \alpha_{2}}-\frac{S_{1}}{\sin \alpha_{1}}}{\frac{S_{2}}{\tan \alpha_{2}}-\frac{S_{1}}{\tan \alpha_{1}}}\right)
$$

In this study, the flip angles $\alpha_{1}=11^{\circ}$ and $\alpha_{2}=56^{\circ}$ were used to acquire the signals $S_{1}$ and $S_{2}$, respectively.

$T_{2}^{*}$ was determined by applying two different values of $T_{E}$ and subsequently solving the following equation to fit the signals obtained in the resulting image.

$$
M_{X Y}(t)=M_{0}\left(1-\mathrm{e}^{-t / T_{2}^{*}}\right)
$$

In this study, $T_{E}$ values of 0.87 and $1.2 \mathrm{~ms}$ were used, and the obtained $M_{X Y} \mathrm{~s}$ were substituted into Equation (4) to determine $T_{2}^{*}$. The resulting relaxation curves for $T_{1}$ and $T_{2}^{*}$ are illustrated in Section 4.1 for $T_{E}$ and $T_{R}$ set to 1.19 and $8.4 \mathrm{~ms}$, respectively. Although the resolution of constructed images can be improved by repeating acquired signals, a resolution (the size of an imaging voxel) of $1 \times 1 \times 1 \mathrm{~mm}$ was used in this study without repetition because this resolution 
is sufficient to measure the depth of water permeation through cementitious material. The required time to acquire a single image was approximately $2 \mathrm{~min}$.

\section{Results and Discussion}

\subsection{Determining Imaging Parameters}

$T_{1}$ and $T_{2}^{*}$ were studied to determine the optimum parameters for imaging. The signal intensity obtained with $\alpha_{1}=11^{\circ}$ and $\alpha_{2}=56^{\circ}$ were 181 and 697, respectively. Substituting these values into Equation (3) yields $T_{1}=6.88 \mathrm{~ms}$. The signal intensity acquired by implementing $T_{E}=0.87$ and $1.2 \mathrm{~ms}$ were 2207 and 623 , respectively. Subsequently, the value of $T_{2}^{*}$ obtained by substituting the above values into Equation (4) and performing fitting was $0.26 \mathrm{~ms}$. These $T_{1}$ and $T_{2}^{*}$ values are very short as compared to those of bulk water, which are each approximately $2500 \mathrm{~ms}$ [11]. Dissolved ions in water and small pores are known to decrease $T_{1}$ and $T_{2}^{*}$ [8] [12]. Figure 2 shows the calculated relaxation curves for $M_{Z}$ and $\mathrm{M}_{\mathrm{XY}}$ assuming $M_{0}=1 . M_{X Y}$ can be observed to decay faster than $M_{Z}$; $M_{X Y}$ decreased to one-thousandth of $M_{0}$ at $1.8 \mathrm{~ms}$; this indicates that $T_{E}$ and $T_{R}$ should be set small to acquire a strong signal. Thus, in this study, $T_{E}$ and $T_{R}$ were set to $1.19 \mathrm{~ms}$ and $8.4 \mathrm{~ms}$, respectively.

\subsection{Effects of Relative Humidity}

Acquired images of specimens stored at various levels of RH are shown in Figure 3. Images of the specimens maintained at higher levels of $\mathrm{RH}$ are visibly clearer, as indicated by the contrast, while the specimens maintained at $76 \%$ and $85 \%$ RH do not yield a strong contrast. The masses of specimens maintained at $98 \%$ and $100 \% \mathrm{RH}$ exhibited continuing increase at the time of MRI imaging. This result indicates that the specimens maintained at RHs of lower than $85 \%$ did not emit a sufficiently strong signal, and that stronger signals will be acquired from specimens maintained at $98 \%$ and $100 \% \mathrm{RH}$ at constant mass.

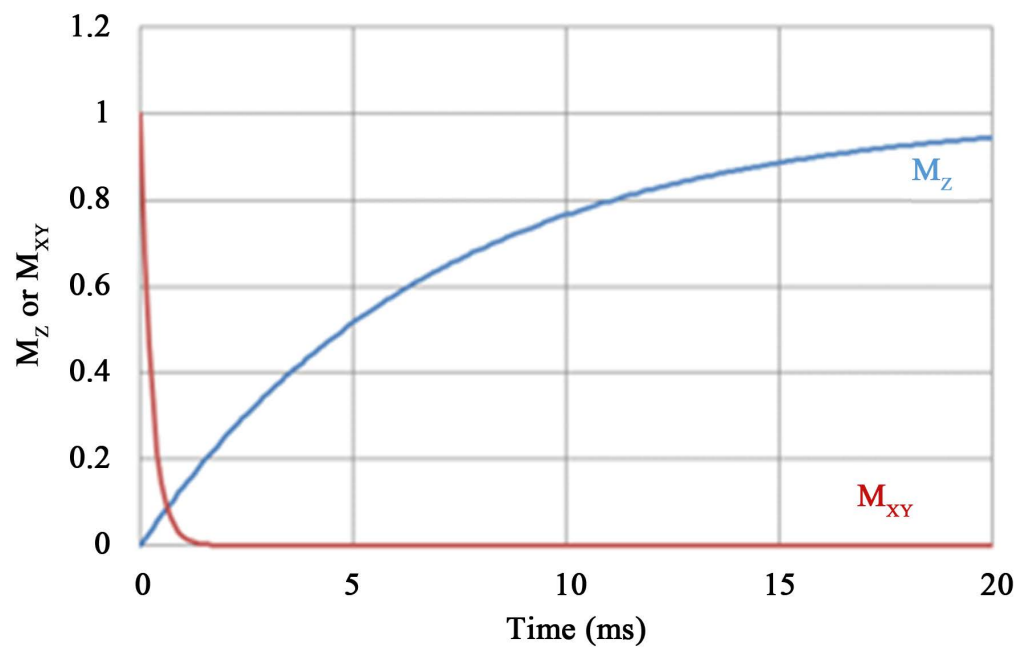

Figure 2. Relaxation curves: $M_{Z}$ and $M_{X Y}$. 


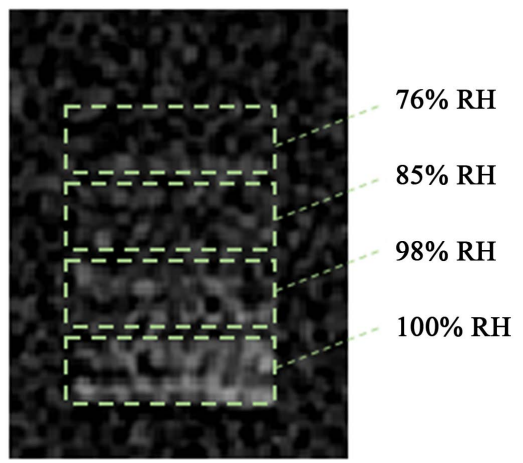

Figure 3. Images of cement pastes under various levels of RH.

The moisture contents of the samples stored at levels of $76 \%, 85 \%, 98 \%$ and $100 \% \mathrm{RH}$ are shown in Figure 4. These results indicate that the volume having a moisture content of more than 0.19 was detected under the conditions in this study. However, it should be noted that the moisture-level threshold for detection obtained in this study may vary according to the MRI device and imaging parameters.

\subsection{Comparison of Permeation Depth Observation Methods}

In Figure 5, the images of HCP made with WPC acquired via MRI, and those of the split surfaces obtained via water leakage detection are shown. In the split surface images, the dark-coloured areas indicate positions of water detection by the water leakage testing agent. Comparison of the results of both methods reveals a good agreement on water permeation depth that is independent of the method of drying. Note that the colours in the captured images differ because the measured positions of the samples differed, which thus yielded a difference in acquired signal strength; the colour difference is not an indication of a difference in water content. Therefore, these results indicate that, although MRI can provide a non-destructive measure of water permeation depth, the distribution of water content may be difficult to acquire because, as shown in Figure 5, the signal strength varies according to position.

\subsection{Effects of Cement Type on MRI Signal}

No signal was acquired from the HCP made with OPC while water was observed on its split surface (Figure 6). Moreover, the permeation depth of HCP made with OPC was lesser than that of HCP made with WPC. This is likely due to the magnetic components in OPC inhibiting the signal such that no water was detected using the measurement conditions in this study [8]. Figure 7 illustrates the pore structures of HCP specimens comprising WPC and OPC that were dried under conditions of $40^{\circ} \mathrm{C}$ and $10 \%$ RH for 2 weeks. HCP made with OPC exhibited a denser pore structure as compared to HPC made with WPC; this difference in porosity is suggested to be the cause of differing permeation depths. 


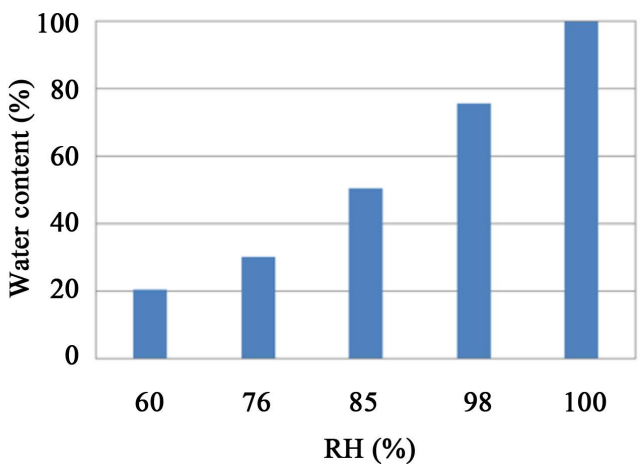

Figure 4. Water content in cement paste as a function of RH.

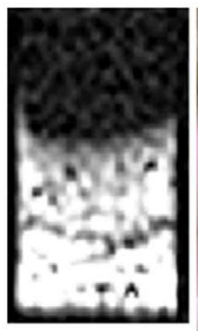

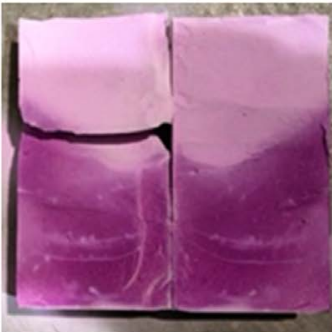

(a)
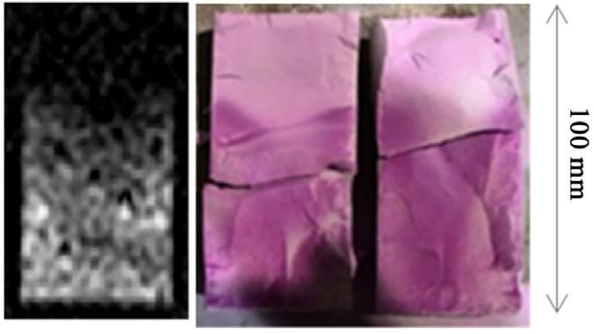

(b)

Figure 5. Comparison of MRI images of HCP made with WPC and splitting surface as obtained via a water detector. (a) Dried at $20^{\circ} \mathrm{C}$ for 1 month; (b) Dried at $20^{\circ} \mathrm{C}$ for 2 weeks.

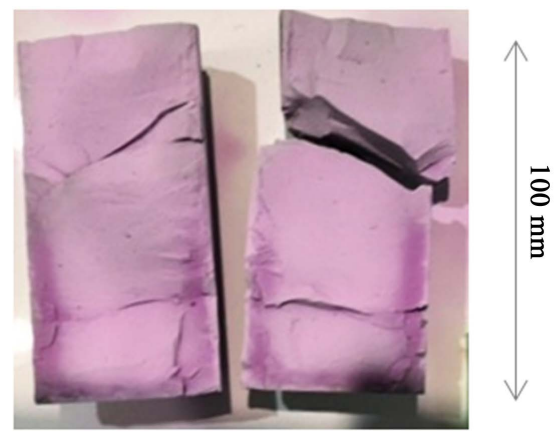

Figure 6. Split surface of HCP made with OPC.

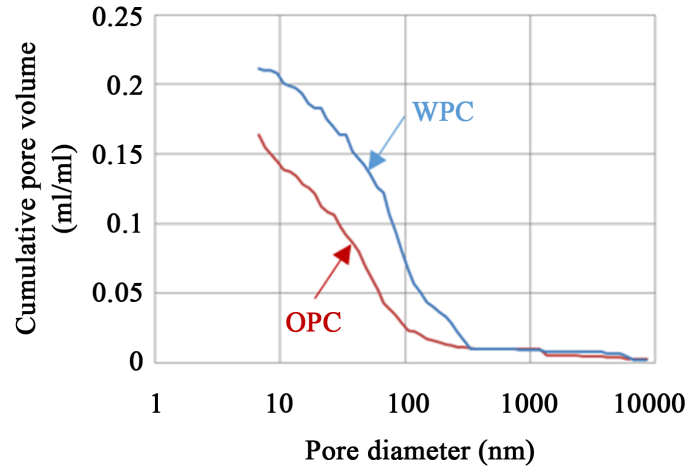

Figure 7. Pore size distribution in HCP. 


\subsection{Effects of Aggregate Type}

We have not provided the captured image of concrete with LWA because no signal was acquired. The acquired images of concrete with LSA at age $48 \mathrm{~h}$ are shown in Figure 8. The seal-cured specimen exhibits a stronger signal than that cured under conditions of $20^{\circ} \mathrm{C}$ and $60 \% \mathrm{RH}$. As these two specimens were identically positioned, the difference in signal intensity is directly proportional to the difference in water content; this can be confirmed by observing Figure 8 (c), which shows that water was not detected in the sample dried at $105^{\circ} \mathrm{C}$.

Figure 9 shows the images of the concrete samples with LSA after having been soaked in water. It can be seen that water permeates deeper within the specimen cured at $20^{\circ} \mathrm{C}$ in $60 \% \mathrm{RH}$ than in the seal-cured specimen, while the specimen dried at $105^{\circ} \mathrm{C}$ was found to have the greatest depth of water permeation. The water permeation profile was observed to be convex, deeper at the centre and shallower along the sides. This convex-shaped water front is presumed to be attributed to the drying of the side of the specimens, because, as shown in Figure 10 , the specimens were soaked in water in a room maintained at a temperature of $20^{\circ} \mathrm{C}$ and $40 \% \mathrm{RH}$. This result indicates that, in water permeation or water absorption test, the sides of the sample must be covered to prevent evaporation of the permeated water through the sides of the sample, thereby affecting the water permeation behaviour and causing it to differ from that observed in an actual concrete member.

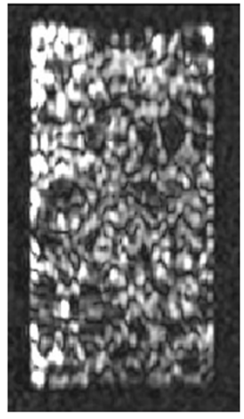

(a)

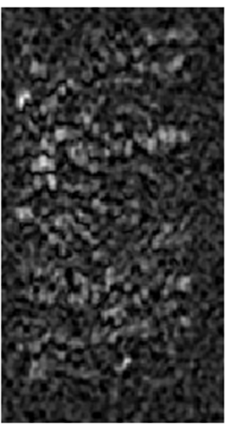

(b)

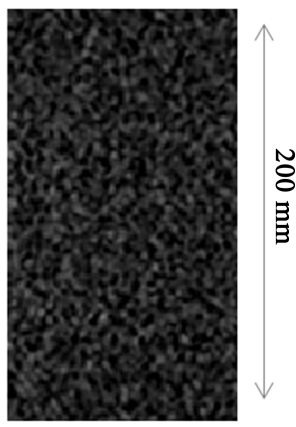

(c)

Figure 8. Images of $\mathrm{HC}$ with LSA; age: $48 \mathrm{~h}$. (a) Seal-cured; (b) $20^{\circ} \mathrm{C} 60 \% \mathrm{RH}$; (c) $105^{\circ} \mathrm{C}$.

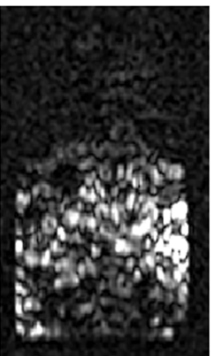

(a)

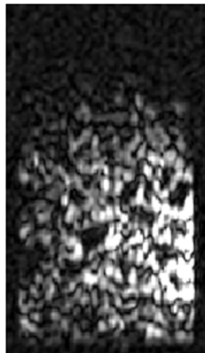

(b)

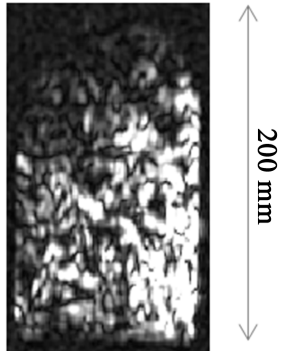

(c)

Figure 9. Images of HC with LSA after being soaked in water. (a) Seal-cured; (b) $20^{\circ} \mathrm{C}$ $60 \% \mathrm{RH}$; (c) $105^{\circ} \mathrm{C}$. 


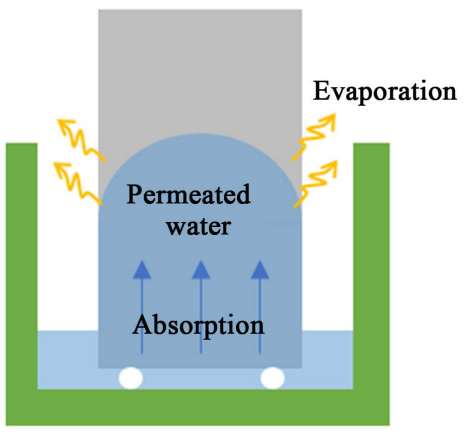

Figure 10. Schematic of water permeation and evaporation in an open-air container.

\section{Conclusions}

Non-destructive imaging of water in cementitious material was performed by implementing MRI; the following results were obtained according to the conditions and parameters used in this study.

- $T_{1}$ and $T_{2}^{*}$, which yielded the relaxation curves for the signal acquired from HCP with WPC, were determined as 6.88 and $0.26 \mathrm{~ms}$, respectively.

- The water permeation through HCP comprising WPC was detected via MRI. The resulting permeation depths as measured via MRI and a water leakage testing agent showing surface splitting demonstrated good agreement.

- In this study, HCP, which has a moisture content of more than 0.19 , was detected via MRI.

- MRI was able to image the moisture loss and water permeation through concrete with LSA, but not in concrete with LWA.

The water permeation depth in concrete with LSA was detected via MRI. The permeation depth increased as the concrete dried, yielding a convex-shaped water front, which is indicative of evaporation of permeated water through the sides of the specimen.

\section{Acknowledgements}

The authors would like to thank Dr. Hironori Nakatani at the Center for Evolutionary Cognitive Sciences at the University of Tokyo and Mr. Katsutoshi Murata at Siemens Healthineers Japan for setting the protocol for MRI. The lime stone aggregate was provided by Sumitomo Osaka Cement. This study was supported by a research grant from the Japan Concrete Institute.

\section{References}

[1] Claisse, P., Elsayad, H. and Ganjian, E. (2009) Water Vapor and Liquid Permeability Measurements in Cementitious Samples. Advances in Cement Research, 21, 83-89. https://doi.org/10.1680/adcr.8.00046

[2] Zhang, S.P. and Zong, L. (2014) Evaluation of Relationship between Water Absorption and Durability Ofconcrete Materials. Advances in Materials Science and Engineering, 2014, Article ID: 650373. https://doi.org/10.1155/2014/650373

[3] Akita, H., Fujiwara, T. and Ozaka, Y. (1996) A Practical Procedure for the Analysis 
of Moisture Transfer within Concrete Due to Drying. Magazine of Concrete Research, 48, 129-137.

[4] Zhang, X. and Zhao, H. (2015) Characterization of Moisture Diffusion in cured Concrete Slabs at Early Ages. Advances in Materials Science and Engineering, 2015, Article ID: 154394. https://doi.org/10.1155/2015/154394

[5] Ueda, H. and Suzuki, H. (2016) Water Penetrability into Concrete Surface and Interface between Concrete and Repair Materials. Quarterly Report of RTRI, 57, 36-41. https://doi.org/10.2219/rtriqr.57.1 36

[6] Justnes, H., Bryhn, K. and Rosvold, G.O. (1994) Neutron Radiography: An Excellent Method of Measuring Water Penetration and Moisture Distribution in Cementitious Materials. Advances in Cement Research, 6, 67-72. https://doi.org/10.1680/adcr.1994.6.22.67

[7] Pleinert, H., Sadouki, H. and Wittmann, F.H. (1998) Determination of Moisture Distributions in Porous Building Materials by Neutron Transmission Analysis. Materials and Structures, 31, 218-224. https://doi.org/10.1007/BF02480418

[8] Marfisi, E., Burgoyne, C.J., Amin, M.H.G. and Hall, L.D. (2005) The Use of MRI to Observe the Structure of Concrete. Magazine of Concrete Research, 57, 101-109. https://doi.org/10.1680/macr.2005.57.2.101

[9] Marfisi, E., Burgoyne, C.J., Amin, M.H.G. and Hall, L.D. (2005) The Use of MRI to Observe Fractures in Concrete. Magazine of Concrete Research, 57, 113-123. https://doi.org/10.1680/macr.2005.57.2.111

[10] Kaufmann, J., Studer, W., Link, J. and Schenker, K. (1997) Study of Water Suction of Concrete with Magnetic Resonance Imaging Methods. Magazine of Concrete Research, 49, 157-165. https://doi.org/10.1680/macr.1997.49.180.157

[11] Hashemi, R.H., Bradley, W.G. and Lisanti, C.J. (2010) MRI: The Basics. Lippincott Williams \& Wilkins, Philadelphia.

[12] Haynes, H. and Holmes, W.M. (2013) The Emerging Use of Magnetic Resonance Imaging (MRI) for 3D Analysis of Sediment Structures and Internal Flow Processes. British Society for Geomorphology, London.

\section{Submit or recommend next manuscript to SCIRP and we will provide best service for you:}

Accepting pre-submission inquiries through Email, Facebook, LinkedIn, Twitter, etc. A wide selection of journals (inclusive of 9 subjects, more than 200 journals)

Providing 24-hour high-quality service

User-friendly online submission system

Fair and swift peer-review system

Efficient typesetting and proofreading procedure

Display of the result of downloads and visits, as well as the number of cited articles

Maximum dissemination of your research work

Submit your manuscript at: http://papersubmission.scirp.org/

Or contact ojce@scirp.org 